\title{
Cognitive focus
}

\author{
Imogen Dickie
}

\begin{tabular}{|c|c|}
\hline Date of deposit & 17092019 \\
\hline Document version & Author's accepted manuscript \\
\hline Access rights & $\begin{array}{l}\text { (c) } 2020 \text { Imogen Dickie. This work is made available online in } \\
\text { accordance with the publisher's policies. This is the author } \\
\text { created, accepted version manuscript following peer review and } \\
\text { may differ slightly from the final published version. }\end{array}$ \\
\hline $\begin{array}{l}\text { Citation for } \\
\text { published version }\end{array}$ & $\begin{array}{l}\text { Dickie, I. (2020). Cognitive focus. In R. Goodman, J. Genone, \& } \\
\text { N. Kroll (Eds.), Singular thought and mental files (pp. 223-250). } \\
\text { Oxford: Oxford University Press. }\end{array}$ \\
\hline $\begin{array}{l}\text { Link to published } \\
\text { version }\end{array}$ & https://doi.org/10.1093/oso/9780198746881.003.0011 \\
\hline
\end{tabular}

Full metadata for this item is available in St Andrews Research

Repository at: https://research-repository.st-andrews.ac.uk/

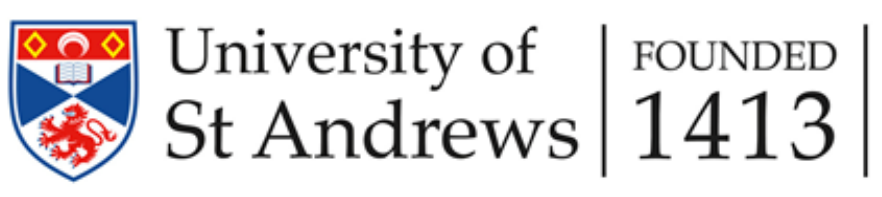




\section{COGNITIVE FOCUS}

\section{Introduction}

Consider a toy example:

Case 1 An astronomer, hereafter ' $A$ ', is compiling a report from the data delivered by a telescope focussed on object $o$ in the night sky. $A$ has verified that the telescope is both focussed and working as it should. The telescope delivers a stream of data: detection of motion; detection of fluctuating temperature; and so on. $A$ compiles her report: 'It's moving. Its temperature is fluctuating between such-and-such values...'

Now consider a question: Is there some object $A$ 's report is about? I take this question to have an obvious answer. The report is about $o-$ the object on which the telescope is focussed. But why is this the case?

Recent philosophical history offers two traditions to which an account of the report's aboutness might appeal. One nudges us towards the suggestion that the report is about $o$ because it is from $o$ that all, or most, of its contents are causally derived. But even adherents to this tradition do not think this suggestion can stand in its initial, simpleminded form. For the initial suggestion leaves us unable to say why the report should count as about $o$ rather than any of a range of entities to which its contents also stand in this relation. For example, the initial suggestion cannot explain why the report is about $o$ rather than the stream of photons that leaves $o$ and arrives at the telescope's photoelectric detector. And if we suppose that $o$ 's properties themselves depend causally on those of some other object, $O^{*}$, the initial suggestion gives no reason to prefer $o$ to $O^{*}$ as the thing the report is about.

Another tradition nudges us towards the suggestion that the report is about $o$ because $o$ is the satisfier of some special, aboutness-fixing, description. But what might this description be? It is implausible that it is constructed just by conjoining all or most of the report's contents: that would entail that the report is about an object only if it is also (mostly) right.

The usual response to the observation that both 'causalist' and 'descriptivist' suggestions are implausible in their initial forms is to look for more sophisticated variants: causalist accounts built around fancier causal conditions; descriptivist accounts built around fancier descriptions; perhaps a hybrid 'causal descriptivist' account, according to which the report is about $o$ because $o$ satisfies a description which specifies some suitable causal relation.

But I submit that there is a simpler answer right in front of us. $A$ 's report is about $o$ because it is upon $o$ that the telescope, and, by extension, $A$ 's whole report-generating method, are focussed. The fact that the telescope is focussed on $o$ does not guarantee that the data it delivers will match $o$. But it does guarantee that these data will match $o$ unless some unlucky spoiler - a dirty mirror; a cracked lens - intervenes. By extension, $A$ 's belief-forming method - the method by which her report is justified - is 'focussed' on $O$ in that $o$ is the unique object whose properties $A$ will be unlucky to get wrong in justifying her report as she does and not merely lucky to get right. Just as the fact that the telescope is (literally) focussed on $o$ does not guarantee that the data it delivers will 
match $o$, the fact that $A$ 's means of justifying her report is 'focussed' on $o$ in the extended sense does not guarantee that her report will get all or even most of $o$ 's properties right. But it does guarantee that the report will get $o$ 's properties right unless some unlucky spoiler intervenes.

This paper develops an account of thoughts about ordinary objects - things like tables, trees, dogs, and people - which treats their aboutness as a kind of focus. Various kinds of relations to ordinary things enable us to think about them. Sometimes the thought-enabling relation involves perceptual contact. Sometimes it involves grasp of a proper name. Sometimes it involves the subject's grasp of a description to which the object is appropriately related. In each case, the aboutness-fixing relation does its aboutness-fixing work by securing what I shall call 'cognitive focus' on the object: by providing a means of justification that converges on the object; a means of justification such that the subject will be unlucky if beliefs justified by this means do not match what the object is like, and not merely lucky if they do.

The next section of the paper argues for a precise version of this suggestion. The third relates the resulting proposal to the traditional debate about singular thought. The paper has an appendix which explains why, though the proposal could have been formulated using the notion of a 'mental file', I have kept the main text free from encroachments by this seductive term.

\section{Aboutness is cognitive focus ${ }^{1}$}

I have suggested that an aboutness-fixing relation does its aboutness-fixing work by securing cognitive focus - by providing a means of justification which converges on a specific object, so that if the subject forms a body of beliefs justified by this means, she will be unlucky to get the object's properties wrong and not merely lucky to get them right. This section develops an argument for a precise version of this suggestion. The argument begins with what I take to be two basic principles:

Principle connecting justification and truth - Justification is truth conducive; in general and allowing exceptions, the better your justification for a belief, the more likely its truth.

Principle connecting truth and aboutness - If a belief is about an object, its truth or falsity depends on what the object is like. (If my belief that Jack has fleas is about my dog, it is true iff he has fleas.)

The claim that aboutness is cognitive focus itself connects justification and aboutness: it is the claim that there is aboutness iff there is justificatory convergence. So the basic form of the argument I am about to present can be represented like this:

\footnotetext{
${ }^{1}$ This section presents an alternative version of the argument of Dickie 2015 Chapter 2.
} 


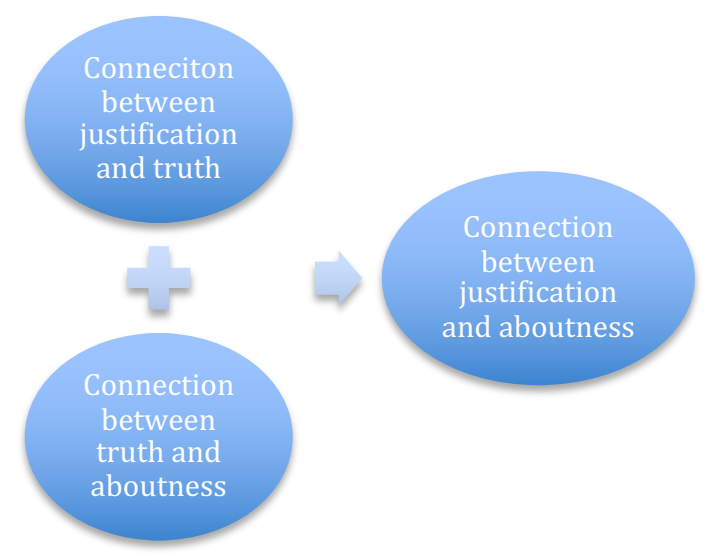

This skeleton statement of the argument brings out the intuitive case for the claim that aboutness is cognitive focus: the claim captures the significance for accounts of aboutness of the fact that justification is truth-conducive.

The rest of the section fills in the details of this intuitive argument. I shall start by providing a more precise version of the justification and truth principle. Then I shall show how the justification and truth and truth and aboutness principles combine to give the 'aboutness is cognitive focus' conclusion.

The version of the justification and truth principle that I am going to employ ${ }^{2}$ is built around a 'bounded rationality' model of our cognitive lives ${ }^{3}$. This model takes its rise from the observation that our cognitive capacities are very limited relative to the complexity of the world around us. Consider some ordinary belief about the world outside the mind, for example, my belief that this paper bag (the one on the table in front of me) contains about a pound of coffee beans. If you asked me what justifies this belief, I would list what seem to me the pertinent factors. I just bought the bag and its contents from a self-professed purveyor of coffee beans from whom I have many times in the past bought very similar bags, all containing around a pound of beans. The bag has ' 1 pound' and 'coffee beans' stamped on it. The purveyor sells only coffee beans in such bags. Together, these factors rule out a wide range of ways my belief might fail to be true. They do not rule out all such ways. For example, they do not rule out the possibility that I am in fact in a virtual reality environment and am not looking at a real paper bag at all. And they do not rule out the possibility that one in every 100000 such bags handed over by this purveyor is in fact a bag of gravel, and today is my unlucky day.

But, though the factors I would list as justifying my belief do not rule out these devious or unusual ways it might fail to be true, it would, at first sight, be strange to suggest that I should therefore have hesitated before forming it - that I should have held back until I had checked that I was not in a virtual reality environment and the bag did not contain gravel. The bounded rationality framework takes this appearance at face value: there are some not-p possibilities that you should rule out before moving to the belief that $\mathrm{p}$, but others that you need not. And in fact (according to this framework) a

\footnotetext{
${ }^{2}$ Others may prefer different precisifications of this principle. Differences between rival precisifications will result in different versions of the claim that aboutness is cognitive focus. But this fine print need not concern us here.

${ }^{3}$ Compare for example Bratman 1987.
} 
possibility that you need not rule out before forming a belief is also one that you should not expend cognitive resources trying to: a subject with limited cognitive resources who squanders them like this will founder in our complex world.

To keep things simple, let us suppose that the circumstances in which a belief that $\mathrm{p}$ would fail to be true divide into two classes: those which should be ruled out before forming the belief, and those which need not be. Let us call circumstances in the first group 'rationally relevant' and those in the second 'rationally irrelevant'. Then the version of the claim that justification is truth conducive that I am going to employ can be put like this. A belief is justified only if formed by a route that rules out some suitably wide range of ways it might fail to be true. It is justified enough to count as rational iff the factors that justify it rule out all the ways it might fail to be true that are rationally relevant, so that where a rational belief turns out false, the mismatch between belief and reality can be traced to some devious or unusual factor against which the subject was not required to be on her guard. ${ }^{4}$

Given this version of the justification and truth principle, we can argue that cognitive focus is necessary for aboutness - wherever there is aboutness there is cognitive focus - as follows:

\section{Suppose}

$1 \mathrm{~S}$ has a belief that $<\mathrm{a}$ is $\mathrm{F}>$, and this belief is about object $o$.

Add the truth and aboutness principle:

2 If $\mathrm{S}$ 's belief that $<\mathrm{a}$ is $\mathrm{F}>$ is about an object, it is true iff that object is $F$.

1 and 2 entail

$3 \mathrm{~S}$ 's belief that $<\mathrm{a}$ is $\mathrm{F}>$ is true iff $o$ is $F$.

Add the justification and truth principle:

4 Justification that secures a belief's rationality eliminates every rationally relevant circumstance where the belief is not true.

3 and $\mathbf{4}$ entail

\footnotetext{
${ }^{4}$ This paragraph brushes over two questions which a full discussion of the relation between truth and justification in a 'bounded rationality' framework would discuss in detail - the question of whether rational relevance is an all-or-nothing matter (I have supposed for simplicity that it is), and that of whether rationality-securing justification must (as I have supposed) eliminate all rationally relevant ways a belief might fail to be true, rather than some suitably large and representative range of them. Different choices on these matters will generate alternative versions of the justification and truth principle, and, therefore, of the conclusion that aboutness is cognitive focus. But my aim here is not to establish a definitive version of the justification and truth principle. It is to bring out the connection between accounts of aboutness and this principle in whatever version is preferred.
} 
5 Justification that secures the rationality of the belief that $<\mathrm{a}$ is $\mathrm{F}>$ eliminates every rationally relevant circumstance where $o$ is not $F$.

We have now derived $\mathbf{5}$ from the supposition at $\mathbf{1}$ together with the justification and truth and truth and aboutness principles. So, taking these principles as given, we can have

6 If S's belief that $<\mathrm{a}$ is $\mathrm{F}>$ is about $o$, justification that secures the rationality of the belief eliminates every rationally relevant circumstance where $o$ is not $F$.

And 6 is just a more precise version of the claim that where there is aboutness there is cognitive focus.

Note that $\mathbf{6}$ does not entail that a rational belief about an object will get the object's properties right. Rather, the suggestion is that where a rational belief about $o$ gets $o$ 's properties wrong, the mistake can be traced to some rational-irrelevance-producing factor - a factor against which the subject was not rationally required to be on her guard. Nor does 6 entail that you can count as thinking about an object only if you have rational beliefs about it. Rather, $\mathbf{6}$ should be read as involving an embedded counterfactual: Suppose you have an $<\mathrm{a}$ is $\mathrm{F}>$ thought about $o$. Then if you had rationality-securing justification for accepting this thought as true, this justification would eliminate every rationally relevant circumstance where o is not $\mathrm{F}$.

Now let us establish the connection in the other direction: where there is cognitive focus there is aboutness. For reasons to be explained below, the argument I shall provide for the connection in this direction is tailored to the cases introduced in $\S 1$ as comprising this paper's central explanatory target: thoughts about ordinary objects of the kinds standardly made available by perceptual links with such objects; understanding of proper names referring to them, and grasp of descriptive conditions to which they are appropriately related. Let us use a perceptual case to get the argument's ingredients on the table:

Case 2 You are in an ordinary situation in which you have no reason to doubt the deliverances of perception. Looking at an orange on the table in front of you, you form, by uptake from perception, a body of beliefs which you treat as about a single thing, and would express using sentences containing 'that': $<$ That is rolling $>$ you think; $<$ That is orange $>$; $<$ That is spherical $>$; $<$ That is about to fall $>$.

I shall take it that your beliefs in Case 2 are justified. And I suggest that it is a feature of Case 2-type situations that, though you may form beliefs which you treat as belonging to the same unified body of beliefs - all about a single thing; all expressible using coreferring tokens of 'that' - which are justified by non-perceptual means, as long as your perceptual link lasts you will treat perceptual justification as trumping non-perceptual. For example, suppose someone you have no reason to doubt arrives, sees what you are looking at, and says 'It is made of glass' and 'It will shatter if it falls'. Then you have 'testimony-based' justification for the beliefs you would express by repeating these sentences: justification by uptake from the utterances of someone you are entitled to treat as reliable. But suppose you now observe the thing fall from a height onto the hardwood floor with a soft thud and roll away. Now you will revise your beliefs towards the perceptual information, perception trumping testimony. 
This case illustrates what I suggest is a basic feature of our ordinary bodies of belief about ordinary things. Such a body of beliefs is associated with what I shall call a 'proprietary' means of justification: a means of justification treated by the subject as trumping all others. ${ }^{5}$ For the bodies of belief standardly made available by perceptual links with ordinary things and standardly expressed using 'this' or 'that', proprietary justification is by uptake from the deliverances of the perceptual link. Cases 3-4 illustrate the parallel point for the other cases in the target range - thoughts about ordinary things whose aboutness is mediated by the subject's grasp of a proper name or a descriptive condition:

Case 3 You have not heard the name 'Aneurin Bevan' before. Somebody begins to explain who Bevan was: 'Aneurin Bevan was a British Labour Party politician. He was a long-standing member of parliament, and a cabinet minister in the 1940's and 50's. He was instrumental in the foundation of Britain's National Health Service.' Nothing about the situation leads you to doubt your informant's reliability. You take the utterances at face value, forming a body of beliefs you treat as about a single thing, and which you would use the name 'Aneurin Bevan' to express.

Case 4 'Tremulous Hand' is used to refer to the otherwise unidentified author of around 50000 Thirteenth Century glosses in manuscripts. Paleographical analysis provides strong evidence that these glosses are the work of a single person with distinctive (tremulous and left-leaning) handwriting. All that is known about Tremulous Hand is what can be deduced from the glosses themselves. You are introduced to the name 'Tremulous Hand', and set about trying to make your contribution to medieval manuscript scholarship, looking for evidence as to what the author of the glosses was like, and marshalling your findings into a body of beliefs you treat as about a single thing.

In Case 3, the proprietary means of justification is uptake from the utterances of an apparently reliable (or not apparently unreliable) informant. In Case 4, it is use of the description to harvest information, building up a body of beliefs whose contents you take to match what the satisfier of the description is like. In each case, you might add beliefs justified by non-proprietary means. What makes the proprietary means of justification proprietary is its trumping status: the fact that where proprietary and non-proprietary means of justification deliver conflicting results, the proprietary means carries the day. ${ }^{6}$

Given the notion of proprietary justification, we can argue for a restricted version of the claim that where there is cognitive focus there is aboutness:

1 Suppose that subject $\mathrm{S}$ is maintaining a body of beliefs of the kind illustrated by Cases 2-4 - a body of beliefs which has a proprietary means of justification (justification by uptake from a perceptual link; justification by uptake from a stream of testimony; justification from description-based cognition), and which the subject treats as about a

\footnotetext{
5 The notion of proprietary justification has precursors in Dummett's notion of canonical verification (1978 312-315; 1991 177-179 and 246-247) Evans's notion of a 'controlling conception' (1982 145, 174); Campbell's notion of a 'dedicated' path to justification (1999); and Recanati's notion of the 'special way of gaining information' associated with a mental file (2010 157; 212 34-38).

${ }^{6}$ In more structurally complex cases (for example, where a subject uses a proper name to refer to an object to which she has occasional perceptual demonstrative access) the suggestion will be that a body of beliefs might have different means of justification proprietary at different times. This suggestion requires a notion of continuity for means of justification associated with a single body of beliefs. I take some steps towards meeting this requirement for the case of descriptive names at Dickie 2015 pp 225-7. Stojnic (2018) raises concerns about the notion of proprietary justification to which this note is a preliminary response.
} 
single thing. And suppose that the proprietary means of justification for this body of beliefs converges on ordinary object $o$.

2 There are three possibilities:

2a The subject's beliefs as described in $\mathbf{1}$ are about $o$

2b The beliefs are about some $o^{*} \neq o$.

$2 \mathbf{c}$ The beliefs are about nothing.

But there are good grounds for $\mathbf{3}$ :

3 The subject's beliefs as described at $\mathbf{1}$ are not about some $o^{*} \neq o(\mathbf{2 b}$ can be rejected).

The central element in the case for $\mathbf{3}$ is a uniqueness claim: if there is some object upon which the proprietary justification for a body of beliefs converges, it is the only such object. For example, for perception-based cases like Case 2, the claim is that if you are forming a body of 'that' beliefs by uptake from a perceptual link, and there is some object whose properties this means of justification tends to get right, there is no second object for which this is also the case.

To see why this claim should be accepted, note first that if the kind of means of justification mentioned at $\mathbf{1}$ is to converge on both $o$ and some $o^{*} \neq o, o$ and $o^{*}$ will have to be qualitative duplicates. For macroscopic difference breeds macroscopic difference. Even ordinary objects that begin life differing in only a few macroscopic properties identical twins; manufactured goods from the same production line - soon differ in many of them. So if $o$ and $o^{*}$ are non-duplicate ordinary objects, there are many commonplace possible circumstances in which $o$ has a macroscopic property that $o^{*}$ lacks. But if $o$ and $o^{*}$ differ in their ordinary properties across commonplace possible circumstances, the tests for property instantiation deployed in Cases 2-4 will be reliable across such circumstances with respect to only one of them. (For example, consider the perceptual test for property instantiation involved in Case 2. If there are many commonplace possible circumstances in which $o$ is $F$ but $o^{*}$ not, formation of $<$ That is $\mathrm{F}>$ beliefs by uptake from a perceptual link with ordinary object $o$ will generally rule out commonplace ways $o$ might fail to be $F$, but not do the same with respect to $o^{*}$.)

Now add a contingent fact about our world. Our world does not contain qualitative duplication of ordinary objects which places duplicates anywhere near one another. If there is a qualitative duplicate of you - someone who shares not only all your intrinsic properties (like your height and eye colour) but also all your relational ones (like being ten feet from a black bicycle), this person is neither on our planet nor anywhere near us in the universe. It is consistent with everything we know that ordinary material things in our world do have qualitative duplicates. But this is because it is consistent with what we know that the universe repeats itself. Though you have no qualitative duplicate anywhere near here, you might (for all we know) have one in some distant sector of the universe where duplicates of our own sector's inhabitants play out a duplicate history.

Putting these elements together, we have an argument for the uniqueness claim. The proprietary means of justification illustrated by Cases 2-4 can converge only on objects in the subject's own sector. For the hypothetical other sectors are (by hypothesis) sectors whose existence is ruled neither in nor out by our ordinary means of justifying our 
beliefs. But if one of these means of justification is to converge on both $o$ and some $o^{*} \neq$ $o, o$ and $o^{*}$ must be qualitative duplicates. And there is no qualitative duplication within our own sector. So there are no cases where the proprietary means of justification illustrated by Cases 2-4 converge on more than one thing. ${ }^{7}$

With the uniqueness claim in place, it is a short step to the argument for 3. Suppose that $\mathbf{3}$ is false: S's beliefs as described in $\mathbf{1}$ are about some $o^{*} \neq o$. But proprietary justification for a body of beliefs can converge on only one object. And in the case described at 1 it converges on $o$. So it does not also converge on $o^{*}$. So 1 , the uniqueness claim, and the claim that S's beliefs are about some $o^{*} \neq o$ entail that S's beliefs are about an object $\left(o^{*}\right)$ upon which their proprietary means of justification does not converge. And that contradicts the claim connecting aboutness and cognitive focus we have already established: the claim that where there is aboutness there is cognitive focus.

And there are also good grounds for 4:

4 The beliefs are not about nothing ( $2 \mathrm{c}$ can be rejected).

To bring out the case for $\mathbf{4}$, we must say a little about what kind of factor renders a circumstance rationally irrelevant to formation of a belief. It is tempting to hope for a reductive answer to this question - an answer that will let us say which circumstances are rationally relevant without appealing to the notion of rationality, and, therefore, to explain the notion of rationality for belief in terms of that of elimination of an appropriate range of belief-not-true circumstances. However, though establishing this point would take us too far afield, the history of epistemology does not encourage optimism about the prospects for such a reductive answer. ${ }^{8}$ Rather, what makes a belief rational and what makes a circumstance rationally relevant are going to be explained in terms of one another: the rationally relevant not-p circumstances are those that must be eliminated by justification that secures the rationality of the belief that $\mathrm{p}$; a rational belief is one justified by means that rule out every rationally relevant way it might fail to be true.

But to give up on a reductive account of what makes a circumstance rationally irrelevant is not to give up on any account at all. And we can - without commitment to any reduction - note that rational-irrelevance-generating factors are going to fall under two general heads. ${ }^{9}$

Firstly, there will be factors to do with the usual distribution, in the environment the subject occupies, of the properties concerning which she is in the business of forming beliefs. If you have limited cognitive resources, and are in the business of forming beliefs as to whether things around you are $F$, you are rationally required to test for ordinary hum-drum ways they may be or fail to be $F$. You are not rationally required to test for ways things may be or fail to be $F$ that are arcane or radically unusual. (Recall the bag of coffee example - in an ordinary situation, I am not rationally required, before forming the

\footnotetext{
${ }^{7}$ Dickie 2015 Ch. 2 Appendix A develops this argument in more depth, and connects it with Strawson's famous discussion of 'massive reduplication' in Strawson $1959 \mathrm{ch} 1$. I address complications generated by the 'problem of the many' in Dickie 2015 §1.2.6.

${ }^{8}$ Compare Conee and Feldman 1998.

${ }^{9}$ Here I am in step with Greco's distinction between factors that are 'external' and 'internal' to a subject's epistemic agency. See for example Greco 2010.
} 
belief that the paper bag contains about a pound of coffee, to rule out the possibility that I am subject to a prank in which it has been filled with gravel instead).

The second kind of factor that can generate rational irrelevance concerns the subject's belief-forming mechanisms. Consider the mechanisms which are normally reliable in detecting whether F-ness is present at all or whether F-ness and G-ness are present in a single object. We are not rationally required to guard against the possibility that what seems to be an in-good-order iteration of such a mechanism - an iteration that will give a right verdict unless the subject is encountering an arcane or unusual distribution of F-ness (or F-ness and G-ness) in the world - is in fact a disguised instance of some unreliable mechanism instead. (Consider the telescope example from $\S 1$. If the astronomer has carried out all ordinary checks, making her situation one where she seems to be receiving a stream of data from a focussed telescope in good working order - she is not rationally required to undertake further checks to rule out hidden reliabilityundermining factors - non-focus masquerading as focus; a crack in a mirror that is undetectable by ordinary checks for such things, but will distort the data the telescope delivers.)

Now let us take this sketch of the factors that generate rational irrelevance, and return to the case for $\mathbf{4}$. Suppose $\mathbf{4}$ is false. S's beliefs in the situation described at $\mathbf{1}$ are about nothing. Now suppose we embroider the initial description at $\mathbf{1}$ in a way whose consistency it would be perverse to deny given the consistency of $\mathbf{1}$ itself. Suppose that the objects involved in the situation described at $\mathbf{1}$ are all ordinary objects behaving in mundane ways. This is to suppose that the situation does not involve the first kind of rational-irrelevance-generating factor. Suppose also that the beliefs $\mathrm{S}$ forms in the situation described at $\mathbf{1}$ in fact $d o$ get $o$ 's properties right, and do so because their means of formation in fact is tracking, and tracking reliably, the distribution of properties in S's environment. This is to suppose that the situation does not involve the second kind of rational-irrelevance-generating factor. Finally, suppose that at least one of the beliefs $\mathrm{S}$ forms is rational. Given the supposition that $\mathbf{4}$ is false, this belief is about nothing, so not true: $\mathrm{S}$ has a rational but untrue belief. The justification and truth principle entails that the situation must, therefore, involve some rational-irrelevance-generating factor. But our suppositions already add to the conclusion that no such factor is in play. So the supposition that $\mathbf{4}$ is false entails the consistency of what is in fact an inconsistent situation. ${ }^{10}$

Now let us go back to $\mathbf{2} . \mathbf{2}$ identified three options: the beliefs described at $\mathbf{1}$ are about $o$ (2a); they are about some $o^{*} \neq 0(\mathbf{2 b})$; they are about nothing (2c). We have ruled out $\mathbf{2 b}$ and $\mathbf{2 c}$. So we can move to $\mathbf{5}$ :

5 S's beliefs as described at $\mathbf{1}$ are about $o$.

And that completes the case for the conclusion that, in the target range of cases thoughts about ordinary objects of the kinds standardly made available by perceptual links with such objects; understanding of proper names referring to them, and grasp of descriptive conditions to which they are appropriately related - cognitive focus is

\footnotetext{
${ }^{10}$ I provide an alternative, full dress version of the argument for $\mathbf{4}$, free from the assumptions about which kinds of factors can generate rational irrelevance, in Dickie 2015 Ch. 2 Appendix B, and a third version, adapted to a virtue reliabilist framework, in Dickie forthcoming.
} 
sufficient for aboutness: where proprietary justification for a body of ordinary beliefs converges on $o$, the beliefs are about $o$.

Putting the two phases of the argument together, we get the precise version of the claim that aboutness is cognitive focus that I want to propose:

Aboutness is cognitive focus A relation between a body of $<\mathrm{a}$ is $\mathrm{F}>$ beliefs and ordinary object $o$ secures $o$ as the object the beliefs are about by making available a proprietary means of justification which converges on $o$, so that a situation where the subject forms an $<$ a is F $>$ belief whose rationality is secured by this means is either a situation where $o$ is $F$, or one that is rationally irrelevant.

I repeat that the proposal does not require that a subject thinking about an object have any rational beliefs about it. Nor does it require that the subject have any beliefs justified by the proprietary means. Either of these consequences would be a mark against a view that entailed it. Imagine a case where you are keeping perceptual track of something visible only as a speck on the horizon, and wondering what it is. Because the thing is visible only as a speck an indeterminate distance away, you prudently hold back from forming any $<$ That is F $>$ beliefs. Nevertheless, this is a situation where you are thinking about the thing: if you make the speculation you would express by saying 'Perhaps it is a windmill', your speculation will be correct iff the thing is a windmill. According to the proposal of this section, you count as thinking about the thing in this case because if your situation were to evolve in such a way that it became rational to form $<$ That is $\mathrm{F}>$ beliefs by uptake from your perceptual link - if the thing were to move closer, putting you in a position to form beliefs you would express by saying 'That is red'; 'That is shiny', 'That is moving fast' - these beliefs would match the properties of the thing at the other end of the perceptual link unless some unlucky spoiler intervened. ${ }^{11}$

I shall close the section by considering one aspect of the discussion so far which may have given the reader pause: the appeal to the notion of 'proprietary' justification. This appeal restricts the generality of the account of aboutness-fixing I have proposed to cases where this notion applies. And there is a standpoint from which this restriction will appear to undermine the account's credentials. This is the standpoint of philosophers who suppose that a right account of aboutness-fixing must apply across the board to thought about ordinary objects, places, times, electrons, events, numbers, and in any other case where the pretheoretic label 'thought about a thing' seems to apply. ${ }^{12}$ From this perspective, if the connection between aboutness and cognitive focus can be established only against a background specific to ordinary thoughts about ordinary things, it cannot be fundamental to a right account of aboutness.

However, though I shall not attempt the survey that would be required to argue for this claim, I suggest that this general approach - supposing univocality and looking for a univocal account - has not generated happy results. And the principles from the start of the section generate both a diagnosis as to why this might have been, and a motivation for the procedure I have adopted instead. Recall that the basic principles connected justification and truth, on the one hand, and truth and aboutness on the other:

\footnotetext{
${ }^{11}$ For further discussion see Dickie 2015 pp. 57-64.

12 Quine 1960, Davidson 1967, Lewis 1974, Williams 2007, Crane 2013.
} 
Principle connecting justification and truth - Justification is truth conducive; in general and allow exceptions, the better your justification for a belief, the more likely its truth.

Principle connecting truth and aboutness - If a belief is about an object, its truth or falsity depends on what the object is like.

Given these principles, we should at least suspect that there will be a fundamental connection between what it takes for a belief to be justified and what makes it about one object rather than another. But it is a familiar observation that different models of justification seem suited to different fields of inquiry. For example, it is widely held that justification in the construction of scientific theories is 'holistic' - a scientific hypothesis is never confirmed by empirical data on its own; its confirmation is always relative to a background of other scientific hypotheses. In contrast, it is very implausible that justification in cases like Cases 2-4 is 'holistic' in anything like this sense. But if there are deep connections between aboutness and justification, and major differences between the patterns of justification characteristic of different areas of inquiry, the univocalist methodology - looking for an account of aboutness-fixing under the assumption that it must apply to all cases - is just a recipe for failure.

This section has developed an alternative which takes its rise from an observation that has a long history in philosophical discussion of particulars and thought about them: the observation that ordinary material objects - 'middle sized dry goods' - are the central exemplars of the category of particular things. This observation invites a suggestion as to what counts as a particular: the category of particulars includes ordinary material objects and entities relevantly similar to them. And it invites a parallel suggestion concerning accounts of thought about particulars. The central examples of thoughts about particulars are the simplest thoughts about ordinary material things. The first explanatory task for an account of how aboutness-fixing works is to explain how it works in this kind of basic case. With this explanation in place, we will then be able to turn to cases whose status as involving thought about particular things has traditionally been regarded as up for grabs. Do we think 'about' particular places in the same sense as we think 'about' particular ordinary things? What about particular events or ideas, or particular numbers? What about fictional characters like Dorothea Brooke or mythical entities like Pegasus? Though the proposal of this section has been developed for the case of ordinary thoughts about ordinary things, it also provides a template for assessment of the aboutnessinvolving credentials of these outlying cases: the extent to which an outlying case involves aboutness-fixing and, therefore, aboutness depends on the extent to which the aboutness-fixing story we have told for central cases applies to the outlier too.

\section{$\S 3$ Cognitive focus is singular thought ${ }^{13}$}

I have proposed an account of aboutness in terms of what I have called 'cognitive focus': a body of beliefs is about an object iff its proprietary means of justification converges on the object, making the object the unique thing whose properties the subject will be unlucky to get wrong and not merely lucky to get right if she forms beliefs justified in this way. This section relates the proposal to the traditional debate about

\footnotetext{
13 This section develops some of the lines of thought from Dickie 2015 ch. 6 and 7.
} 
singular thought. I shall argue that singular thoughts just are thoughts that are 'about' objects in the sense of 'aboutness' that the previous section explained. I shall start by saying a little to introduce the traditional debate about singular thought. Then I shall explain why I think the notion of aboutness I have brought out is what believers in singular thought have been looking for all along.

The traditional debate about singular thought traces to a distinction made by Russell. Consider the class of thoughts whose truth or falsity depends on what some particular thing in the world is like (so that the members of the class are all and only the thoughts for which there is some property $F$ and some object $o$ such that whether the thought is true depends on whether $o$ is $F$ ). Russell divided this class in two. On one side, he put thoughts whose truth or falsity depends on what the relevant object is like because the thought characterizes the object. On the other, he put thoughts that belong to the original class not because they genuinely characterize some particular object, but because of how they characterize the world's pattern of property instantiation. For example, consider the thought expressed by an utterance of the sentence 'The author of this paper is a New Zealander', made with no special stage-setting in a situation where the paper you are currently reading is the paper in question. Since the paper has a unique author, the thought is true iff this person is a New Zealander. But, according to Russell, the thought does not genuinely characterize the author. Rather, it characterizes the world's pattern of property instantiation: it would be more accurately expressed by the sentence 'The property is an author of this paper is both uniquely instantiated and co-instantiated with is a New Zealander'. ${ }^{14}$

Subsequent discussion of singular thought has been centred on whether Russell's distinction withstands scrutiny, and, if it does, how exactly the distinction between 'singular' thoughts, which genuinely characterize particular things, and 'general' thoughts, which do not, is to be drawn. ${ }^{15}$ One important strand in this discussion has been the suggestion that singular thoughts are 'object dependent'. Suppose (with Russell) that a thought is genuinely about an object iff thinking it involves having the object 'before the mind' in a sense that it is the aim of discussions of singular thought to explain. Then the state of having such a thought is irreducibly relational: it is a state you cannot be in without being related to some object. (Compare the state of standing next to a tree: you cannot be in this state unless there is a tree next to which you are standing.) So, according to philosophers developing Russell's distinction this way, the availability of a genuinely singular thought entails the existence of an object it is about. ${ }^{16}$

The proposal of $\$ 2$ belongs to this 'object dependence' tradition. I have suggested that the aboutness of our thoughts about ordinary objects is cognitive focus. But cognitive focus is a relation. To be in a state of cognitive focus is to stand in a relation to an object upon which you are cognitively focussed. And when a state is in this way irreducibly relational, it is a state you cannot be in without the existence of an object to which you are related.

\footnotetext{
${ }^{14}$ See for example Russell 1956b p 51, 1956a pp234, 247-248.

${ }^{15}$ For recent accounts of the debate from rival perspectives see Bach 2010, Jeshion 2010, Recanati 2010, Recanati 2012 pp 3-26.

${ }^{16}$ McDowell 1977, 1984; Evans 1982, 1985; Taylor 2000; Braun 2005; Bach 2010, Garcia-Carpintero 2010, Recanati 2010.
} 
The rest of this section explains this aspect of the 'cognitive focus' proposal. I shall first say a little more about how I am suggesting that the notion of object dependence should be understood. Then I shall explain in more detail how the claim that aboutness is cognitive focus entails that thoughts 'about' particulars are object dependent and, therefore, singular.

Recall Case 2 from the previous section: you are looking at an orange on the table in front of you and forming beliefs you would express by saying things like 'That is round'. Now suppose we ask what it would take for the belief you express by saying 'That is round' in this situation to be true. The following are all answers to this question, some more informative than others:

1 The belief is true iff the conditions for such a belief to be true in the situation in which it is held are met.

2 The belief is true iff there is some object which meets the aboutness-fixing conditions for a perceptual demonstrative belief formed in the situation, and this object satisfies the condition that an object must satisfy if a belief ascribing roundness to it is to be true.

3 The belief is true iff the perceptual link that underpins proprietary justification for the body of beliefs of which it is a part is focussed on the object, and this object is round.

4 The belief is true iff $o$ is round (where $o$ is the orange you are looking at).

1-4 form a progression, with later stages filling in details left open at earlier ones ${ }^{17}$. I have omitted possible intermediate stages. And there is room for wrangling about how the details at each stage should go. But for our purposes, what is important is a contrast between the final stage (4) and its predecessors. Each of 1-3 is a legitimate answer to the question 'What would it take for the belief to be true?' In this sense, each states a 'truth condition' for the belief. But only 4 states what I shall call a 'purely worldly' truth condition. 4 is a biconditional which puts the belief on one side and the world on the other, and states a way the world considered aside from the belief must be if the belief is to be true. In contrast, each of 1-3 states a biconditional which mentions the belief itself on the right hand side. It states a relation between the belief and the world whose holding is necessary and sufficient for the belief's truth. It would be mere prejudice to declare that 1-3 are not statements of truth conditions. But they do not state purely worldly truth conditions: they do not characterise a way the world considered aside from the belief would have to be for the belief to be true.

Now consider a different kind of mundane case - the case of the belief expressed by an utterance of 'The $\mathrm{F}$ is G' made by a competent speaker in an ordinary situation with no special stage-setting. Again, suppose we ask what it would take for this belief to be true. As in the previous case, we can give a progression of more specific answers to this question:

1 The belief is true iff the conditions for such a belief to be true in the situation in which it is held are met.

${ }^{17}$ This progression is modeled, with modifications, on Perry 1997 pp 608-9. 
2 The belief is true iff some object is introduced as relevant to its truth or falsity by the description 'the F', and this object satisfies ' $G$ '.

3 The belief is true iff there is a unique object that is $F$, and this object is $G$.

(Supposing that $o$ is the unique $F \ldots$ )

4 The belief is true iff $o$ is $G$.

And, as in the previous case, we can point to a transition in the progression: from statements of how the belief must relate to the world if it is to be true to statements of purely worldly truth conditions. But there is also an obvious contrast between the two progressions. In the first, the transition to purely worldly truth conditions occurs between 3 and 4 , at the same point as the step to a specification that picks out a particular object and says how this object must be if the belief is to be true. In the second progression, in contrast, the step to purely worldly truth conditions occurs between 2 and 3.3 states a purely worldly truth condition. But this is not a condition on some particular object. It is a condition on the world's configuration of properties -3 says that the belief is true iff $F$ is both uniquely instantiated and coinstantiated with $G$.

I suggest that the notion of an object-dependent thought should be understood in terms of the contrast that I have just brought out. A token thought is 'object-dependent' iff it has no purely worldly truth condition that does not characterize an object upon whose properties its truth or falsity depends, so that the thought has a purely worldly truth condition only if there is an object it is about. ${ }^{18}$

Here are two examples to clarify this suggestion and bring out how it relates to the proposal of $\S 2$ :

Case 5 - You are having an experience indistinguishable by you from an experience of a rectangular thing in the middle distance. You have no reason not to take your experience at face value. You form the belief you would express by saying 'That is rectangular'. In fact, your experience as of something rectangular is caused by a freak combination of a speck on your glasses, a far-off tree, and a building on the horizon.

Case 6-1970's BBC regulations allowed scriptwriting credits to be assigned only to a show's initial scriptwriters, so where a change was made by someone outside this initial group, it could not be credited to its author. Instead, the presence of such a change would be indicated by adding 'David Agnew' - a name introduced for this purpose - to the list of contributors to the script. Seeing 'David Agnew' appear repeatedly in $\mathrm{BBC}$ credits from this era, and ignorant of the story behind the name, you ask X, whom you have always found a reliable informant, and whom you know to have worked at the BBC in the 1970's, whether he knew David Agnew. X says 'Yes', and provides you with a range of details. You end up with beliefs you would express by saying things like 'David Agnew was from Bristol'; 'David Agnew was an old Etonian'; 'David Agnew was about 60 in 1975'.

According to the proposal of $\S 2$, these are both cases of aboutness failure. In each case, you are essaying thoughts which will be about a particular object iff their associated proprietary means of justification - uptake from the perceptual link in Case 5; uptake from the stream of testimony in Case 6-converges on the object. In neither case is there

${ }^{18}$ Compare Dickie 2015 pp. 254-263. I take this account of object-dependence to be in broad agreement with the proposal of the first half of Recanati (forthcoming). 
justificatory convergence. So in each case aboutness fails. (In intuitive terms, these are like cases in which it seems that a telescope is focussed on an object but really it is not.) And, because there is aboutness failure in each case, in neither do the beliefs you form have purely worldly truth conditions. The beliefs do have 'truth conditions' in the ecumenical sense of this term that I have allowed. We can give truth-condition-stating clauses like these:

The belief you express by saying 'That is rectangular' is true iff there is some object upon which justification by uptake from the associated perceptual feed converges, and this object is rectangular.

The belief you express by saying 'David Agnew was an old Etonian' is true iff there is some person upon whom justification by uptake from the 'David Agnew' stream of testimony converges, and this person was an old Etonian.

However, these clauses do not put the belief on one side and the world on the other and say how the world must be if the belief is to be true: they do not state purely worldly truth conditions. In each case, the beliefs formed belong to object-dependent types. They are beliefs that will have purely worldly truth conditions only if there are objects they are about.

But why think that the notion of object dependence I have explained is the notion relevant to the distinction between singular and general thought? To answer this question, let us return to the initial statement of the distinction from earlier in this section.

Recall that in introducing the distinction we began with the overall class of thoughts for which there is some object $o$ and some property $F$ such that the thought is true iff $o$ is $F$, and divided this class into two. Singular thoughts, according to the distinction as initially drawn, are thoughts whose truth depends on what some specific object is like because this is the object the thought characterises. So where a token thought belongs to a singular type, if there is no object the token thought is about - no object it characterises - the question 'What must the world be like if this thought is to be true?' has no answer. In this case, the question 'How must the thought relate to the world if it is to be true?' still has an answer. So the thought has 'truth conditions' in the ecumentical sense. But it does not have purely worldly truth conditions.

In contrast, according to the distinction as initially drawn, when the truth of a general thought depends on what some particular object is like, this is not because the thought characterises the object. It is because of (a) how the thought characterises the pattern of property instantiation, and (b) how the object happens to fit into this pattern. (When you think that $<$ the $\mathrm{F}$ is $\mathrm{G}>$, you are representing the world as being such that $F$ is both uniquely instantiated and coinstantiated with $G$. If the truth or falsity of your thought depends on what some unique object is like, this is because the object is the unique $F$.) So a general thought just is a thought whose truth or falsity may depend on whether some specific object is $G$, but which will have purely worldly truth conditions regardless of whether any specific object is relevant to its truth or falsity in this way.

I have explained how the proposal of $\S 2$ entails that perceptual demonstrative thoughts and proper name based thoughts are irreducibly relational, therefore object dependent, therefore singular. I shall now argue that the same diagnosis applies to the 
third kind of case discussed in $\S 2$ - cases where aboutness is mediated by the subject's grasp of a description.

Recall our example of a case of this kind: the case of the thoughts expressed using the name 'Tremulous Hand'. 'Tremulous Hand' is a 'descriptive name' - a name introduced into a language by a stipulation that it is to be used to refer to the satisfier of an associated description. (In the 'Tremulous Hand' case, the stipulation is "TTremulous Hand" refers to the author of these glosses'.) According to most philosophers who have discussed this issue, if a descriptive name refers at all it refers to the satisfier of the associated description, and this is also the individual the thoughts expressed using the name are about. ${ }^{19}$

But if the aboutness-fixing relation for the scholars' 'Tremulous Hand' thoughts is in this way 'satisfactional', the progression in specifications of truth conditions for a 'Tremulous Hand is F' belief will contain a clause like this:

(A) The belief that $<$ Tremulous Hand is $\mathrm{F}>$ is true iff there is a unique author of the glosses and this person is $F$.

This is a purely worldly truth condition. But it is not a condition on some particular object. So, given the account of 'object dependence' I have proposed, the standard account of descriptive names entails that they do not express object dependent thoughts.

This leaves a proponent of the standard view with two options: deny that singular thoughts are object dependent; or deny that the thoughts we express using descriptive names are singular. Both options have been upheld by protagonists in the debate. ${ }^{20}$ But the proposal of this paper generates an alternative: the standard view is wrong; the thoughts we express using descriptive names are object dependent, and are, therefore, 'singular' in just as rich a sense as perceptual demonstrative and proper-name-based thoughts are.

The reader can perhaps already see from a distance how the proposal generates this result. In outline, the point is that the proposal treats a case of descriptively mediated aboutness-fixing as one where a description mediates cognitive focus on an object, and whether a description is mediating cognitive focus on $o$ does not depend on whether $o$ is the description's satisfier. But the central suggestion here - that descriptively mediated cognitive focus is one thing and satisfaction of a description another - needs more explanation, which I shall now provide.

Let us introduce the term 'description-based cognition' to cover all cases where a subject's route to belief-formation includes a calculation as to what the satisfier of some description is like. Then the current suggestion is that there are two belief-forming activities in which we deploy description-centred cognition, distinguishable by the aims with which we engage in them. Sometimes when we engage in description-centred cognition, we are aiming to characterize the pattern of property instantiation in the world. In these cases, the beliefs we form are general beliefs, not genuinely about particular things. (It actually takes some care to describe a pure case of this kind. This note provides

\footnotetext{
19 Evans 1982; Campbell 2002; Recanati 2012; Jeshion 2004, 2010; Reimer 2004; Goodman 2014.

${ }^{20}$ For the claim that the thoughts we express using descriptive names are not genuinely singular see for example, Evans 1982. For the claim that singular thought is not object-dependent see Jeshion 2002, 2010.
} 
an illustration. ${ }^{21}$ ) But we also form beliefs by description-centred cognition in cases where the aim is not just to find out about the pattern of property instantiation in the world: rather, it is to achieve cognitive focus on some object, and find out what this thing is like. Case 4 'Tremulous Hand' is one example of this kind. In this case, the subject's belief-forming strategy is still built around description-centred cognition. As you build up your body of 'Tremulous Hand' beliefs you make moves like this:

(i) You find evidence that the earliest and latest glosses are dated 70 years apart; add the premiss that even a precocious glossator cannot have been at it before the age of 10; and conclude that Tremulous Hand lived to be at least 80 .

(ii) You note that glosses in French or dealing with French text are absent from the earlier layers of 'Tremulous Hand' marginalia but increasing frequent and confident in successively later ones, and conclude that Tremulous Hand learned French but was not a native speaker of that language.

So you are building up your body of 'Tremulous Hand' beliefs by looking for evidence as to what the author of the glosses was like. But your aim is not just to move towards a right account of which properties are instantiated, uniquely instantiated, and coinstantiated. It is to construct a body of beliefs which is about some specific object, and which gets this object's properties right.

This difference in the aims with which we deploy description-centred cognition generates a difference in truth conditions for the resulting beliefs. For in each kind of case, we are also aiming to form true beliefs - all belief-formation is guided by this aim; truth is, as some philosophers say a 'constitutive aim' of belief ${ }^{22}$. But if the aim that guides your belief-forming activity is also the aim to form true beliefs, the conditions for the truth of your beliefs will be the conditions the meeting of which is necessary and sufficient for the fulfilment of your aim. In the first kind of case of description-centred cognition, the subject's aim is fulfilled (she ends up with true beliefs) iff her beliefs provide a right characterization of the pattern of property instantiation. So beliefs formed in this kind of case have truth conditions that can be stated just in terms of how the belief characterizes the pattern:

21 Imagine an engineer tasked with repairing an intricate machine built from repeated tokens of various component types. Suppose that if the machine is not working, there are two options - it needs to be turned off and on again at the power source, or some component has failed. Suppose the machine is built in such a way that as soon as one component fails, the whole mechanism shuts down to prevent further damage, so that if the problem is a failed component, it is very reliably the case that a single component is to blame. And suppose that, though it is relatively easy to establish that some token of a given component type is broken, it has been found uneconomical to try to find out which individual component is at fault, so that the machine's servicing protocol involves (1) finding out whether something is broken, (2) finding out whether the broken component is (say) an X, and (3) if required, operating a mechanism which replaces all of the components of the faulty type. The tests the engineer runs at (1) and (2) are tests that will yield a positive result iff some one specific component is broken. But the engineer is not in the business of trying to find out about any specific component. Rather, she is testing for a pattern of property instantiation: she is trying to find out whether the property is a broken component is both uniquely instantiated and co-instantiated with is an $X$.

22 Velleman 2000, Boghossian 2003, Shah and Velleman 2005. 
(B) The belief that $<$ the $\mathrm{F}$ is $\mathrm{G}>$ is true iff $F$ is both uniquely instantiated and coinstantiated with $G$.

In contrast, in the kind of case illustrated using 'Tremulous Hand', the subject's beliefforming aims will be fulfilled iff she achieves cognitive focus on some object, and forms beliefs that match what this object is like. So rather than (A) as a statement of truth conditions for 'Tremulous Hand' beliefs we have

(C) The belief that $<$ Tremulous Hand is $\mathrm{G}>$ is true iff the subject's means of justifying her 'Tremulous Hand' beliefs converges on some $o$, and this $o$ is $G$.

Let us use two final examples to emphasise how A-type truth conditions and Ctype truth conditions come apart:

Case 7: 'Geraint the Blue Bard' 'Geraint the Blue Bard' was used for over a hundred years as a name for the otherwise unidentified author of a series of songs in medieval Welsh, dealing with medieval themes, and employing medieval metres. Efforts to find out more about Geraint's life, taking off from cues in the texts, supposed that he flourished in the ninth century, and was either an apothecary, a minor aristocrat, or a priest. Rival factions collected large bodies of evidence to support each of these hypotheses. But in 1956 the 'Blue Bard' songs were shown to be the work of notorious nineteenth century forger Edward Williams.

I take it that there is a reasonably clear intuitive verdict about this case: there was no Geraint; the case involves reference-failure for the name, and aboutness-failure for the beliefs the scholars were using it to express.

Now consider the belief that $<$ Geraint was educated at Carmarthen $>$, formed by one of the scholars before the discovery of the forgery. And consider the contrast between (A)-type and (C)-type accounts of what it would take for this belief to be true:

(A)-type account - The scholar's belief that $<$ Geraint was educated at Carmarthen $>$ is true iff there is a unique author of the ballads, and this person was educated at Carmarthen.

(C)-type account - The scholar's belief that $<$ Geraint was educated at Carmarthen $>$ is true iff the description-based means of justification for the scholars' 'Geraint' beliefs converges on some person, and this person was educated at Carmarthen.

According to the (A)-type account, whether the belief is true depends on whether Edward Williams was educated at Carmarthen. But this is not the intuitive verdict: intuitively, the belief is untrue in virtue of aboutness failure, regardless of whether Williams was educated at Carmarthen. And this intuitive verdict is what the (C)-type account predicts. For consider how the scholar would have justified the belief. The justification would have involved evidence drawn from the ballads, together with justified beliefs about $9^{\text {th }}$ century British history. For example, he might have reasoned as follows. 'There is overwhelming evidence in the ballads that their author never travelled outside Wales. But there is also overwhelming evidence that the author had a specific kind of education. The only place in Wales where such an education was to be had in the $9^{\text {th }}$ century was Carmarthen. So Geraint was educated at Carmarthen.' This means of justification leaves 
whether Edward Williams was educated at Carmarthen a matter of chance. And the same holds for all of the scholars' 'Geraint' beliefs: the proprietary means of justification for these beliefs converges on nobody. But where there is no justificatory convergence, there is no cognitive focus, so no aboutness.

Case 7 illustrates the fact that the beliefs expressed using a descriptive name might fail to be about an object even though the object is the satisfier of the associated description. Another kind of case illustrates how the conditions for descriptivelymediated aboutness and satisfaction of the mediating description come apart in the other direction:

Case 8: 'Gizmo' X, the now aged head of a manufacturing company, likes to boast to his underlings about 'the gizmo that started it all', with strong suggestions that he was himself this thing's inventor. The underlings introduce a descriptive name 'Gizmo' with aboutness-fixing description $<\mathrm{X}$ 's most successful early invention>, and use X's utterances ('Ah, that was the year that the gizmo that started it all really took off' etc.) and the company's financial history to try to work out which of the firm's early patents Gizmo was. (Y suggests that Gizmo was the initial version of the firm's famous self-setting rat trap; Z that it was the jet-fuel valve from which the firm made a lot of money in its early days; and so on.) In fact, though there is an invention that enabled the firm to get on its feet, $\mathrm{X}$ was not its inventor: the firm's early patents were all bought for almost nothing from an unworldly individual who died an obscure emeritus professor in a university town. Y says to Z 'You realise that X didn't invent Gizmo after all'.

Again, I take it that there is a reasonably clear intuitive verdict in this case: there is an object towards which the underlings' investigations were directed, and therefore, a bearer of 'Gizmo'. But this object is not the satisfier of the description that figures in the nameintroducing description: $\mathrm{X}$ has never invented anything, so this description has no satisfier. And, again, this is just the result that (C)-type treatment of the thoughts we express using descriptive names generates: even though the description is not satisfied, the description-based means of justification built around it converges on a particular thing; this is the thing the underlings' 'Gizmo' beliefs are about.

And in fact Case 8 illustrates another respect in which the standard (A)-type treatment is just not providing an accurate account of how descriptively-mediated aboutness-fixing works. Descriptively-mediated aboutness-fixing is aboutness-fixing mediated by description-centred cognition: the subject is maintaining a body of beliefs whose contents are built up by using a description to harvest information and updating the body of beliefs accordingly. In some cases ('Tremulous Hand', 'Geraint') there is one description stipulatively associated with the name, and this is the description around which the description-centred cognition that feeds the body of beliefs continues to be built as the body of beliefs evolves. But there are also cases where there is a fluid relation between the description being used to harvest information and the resulting beliefs. In the 'Gizmo' case, an element of the initial description ('was invented by X') proves fruitless as a source of additions to the body of 'Gizmo' beliefs - the underlings start out both investigating $X$ 's early scientific career and combing the financial records; the first line of inquiry proves frustrating; the second yields rich results; as the inquiry progresses, the 'was invented by X' component ceases to play a role in justifying 'Gizmo' beliefs. In 
other cases, we might find the reverse: a rank-and-file element of the body of beliefs becomes pivotal in the description-centred cognition that feeds it. ${ }^{23}$

The fluidity in the relation between the description being used to build up a body of beliefs and the beliefs themselves sits uneasily with the standard satisfactional view of descriptively mediated aboutness. If the aboutness-fixing story were satisfactional, the aboutness of the body of beliefs would shift with shifts in mediating description, so that the body of beliefs might be about $o$ at time $\mathrm{t} 1, o^{*}$ at $\mathrm{t} 2$, and nothing at $\mathrm{t} 3$, depending on whether and by what the mediating description is satisfied. And this is just a wrong description of examples like Case 8 'Gizmo'. The underlings are looking for a single thing all along, through shifts in the mediating description. So what they were looking for is not identified as this description's satisfier. Rather, what they are looking for all along is the thing upon which their description-based means of justification is, all along, converging.

So the situation is this. We have two models of descriptively mediated aboutnessfixing in play: the standard, satisfactional model, and what I shall call the 'relational' model:

The satisfactional model A body of description-based beliefs is about the satisfier, if there is one, of the associated aboutness-fixing description.

The relational model A body of description-based beliefs is about the object, if there is one, upon which its proprietary means of justification converges. Since their proprietary means of justification is description-centred cognition - forming beliefs in response to evidence as to what the satisfier of some description is like - aboutness-fixing for such bodies of belief is descriptively mediated. But the aboutness of a body of descriptionbased beliefs is not determined satisfactionally. The beliefs are about an object iff, given the subject's informational environment and her description-based justificatory strategy, she stands in a relation of cognitive focus to the object. And this does not require that the object satisfy any description that is actually playing a role in the description-centred cognition that is feeding the body of beliefs.

I have argued that the satisfactional model leaves philosophers trying to develop accounts of singular thought with a familiar choice: deny that singular thought is objectdependent, or deny that a thought whose aboutness is descriptively mediated is genuinely singular. But I have also argued that the satisfactional model should be rejected. The relational model is generated by applying the account of aboutness as cognitive focus for which I argued in $\S 2$ to the case of descriptively mediated aboutness-fixing. And I take it that the from-first-principles argument for the relational model receives at least some additional support from Cases $7-8$ : cases where our intuitions about aboutness seem to lean in the direction the relational model suggests.

But if the relational model of descriptively mediated aboutness-fixing is right, the old choice between denying the object-dependence of singular thought, and denying that

\footnotetext{
${ }^{23}$ Goodman (2014 §7) calls cases like this (where there is, in her preferred terms) fluidity between the ordinary contents of a 'mental file' and the file's 'core cluster' of descriptions cases of 'holistically descriptive' thought. But she maintains that the aboutness-fixing story for such files remains satisfactional, and that the subject's thoughts in this kind of case are not genuinely singular.
} 
there are singular thoughts whose aboutness is descriptively mediated is turned on its head. The relational model treats having a description-based thought about an object as standing in a relation of cognitive focus to the object, so it treats this kind of thought as 'singular' in the same sense as a perceptual demonstrative or proper-name-based thought is singular: you are having a singular thought about an object iff you are cognitively focussed on the object; if you essay such a thought in a situation where there is no object to which you stand in this relation, you are not in a mental state that characterizes a way the world might be. ${ }^{24}$

\section{Appendix The derivative ontology of mental files}

The main body of this chapter has presented an account of singular thought which, though I have avoided the term 'mental file', might well seem a natural fit for a mental files framework. I have said that a body of beliefs of the kind expressed using perceptual demonstratives, proper names, and descriptive names is about $o$ iff its proprietary means of justification converges on $o$, making $o$ the unique thing whose properties the subject would be unlucky to get wrong and not merely lucky to get right if she formed only beliefs justified in this way. Replace 'body of beliefs' with 'mental file', and we have a 'mental files' proposal. So why - the reader might ask - has the author not put things in these terms?

This appendix gives a partial answer to this question: the ontology of mental files is, in a sense to be explained, 'derivative' from that of the activity of maintaining them; it is in terms of the underlying activity rather than the notion of a mental file that an account of aboutness fixing is most perspicuously framed.

I shall start by sketching what is usually taken to be the central explanatory role of the notion of a mental file. Then I shall say why I think this explanatory role compels the metaphysical verdict towards which I have gestured. I should stress that I think much of what I shall say is friendly to many of the views that philosophers who have found it helpful to couch their accounts of singular thought in terms of the notion of a mental file have in common. So what follows is not so much an objection to talk about mental files as an exploration of the extent to which it is an abbreviation for something else.

The central explanatory role of the notion of a mental file can be brought out using the contrast between cases like these:

\footnotetext{
${ }^{24}$ Dickie forthcoming takes a further step towards exploring the implications of this line of thought for a right account of our use of descriptive names, and of the relationship between a descriptive name and its associated description.
} 


\begin{tabular}{|l|l|}
\hline First Case & Second Case \\
\hline $\begin{array}{l}\text { You are receiving a stream of utterances containing tokens of the name 'Russell'. } \\
\text { Nothing about the situation causes you to worry whether your informant is talking } \\
\text { about a single person. 'Russell wrote "On Denoting"', 'Russell worked at }\end{array}$ & $\begin{array}{l}\text { You have been reading on early } \\
\text { Twentieth Century England, and have } \\
\text { Cambridge' says your informant. You form the corresponding beliefs. And you } \\
\text { reason as follows: }\end{array}$ \\
$\begin{array}{l}\text { Russell wrote 'On Denoth a stream of 'Bertie' } \\
\text { testimony and a stream of 'Russell' } \\
\text { testimony. You do not yet realise that } \\
\text { Bertie (Bloomsbury Group socialite) is } \\
\text { Russell (Cambridge philosopher } \\
\text { obsessed with reducing mathematics to } \\
\text { logic). }\end{array}$ \\
\hline Somebody both wrote 'On Denoting' and worked at Cambridge. & \\
\hline
\end{tabular}

On the face of things, the inference in the left hand column is legitimate as it stands: when you move from these premisses to this conclusion, you are rationally entitled to do so. And, on the face of things, the situation described in the right hand column is one in which the parallel inference

Russell wrote 'On Denoting'

Bertie was a Bloomsbury Group socialite

Somebody who was a Bloomsbury Group socialite wrote 'On Denoting'

would not be legitimate: to be in a position to draw this conclusion from these premisses, you must first discover the truth of the identity 'Bertie is Russell'.

Proponents of the mental files framework typically appeal to the notion of a mental file to explain the difference between these cases. The suggestion is that the left hand inference is legitimate as it stands because the premiss beliefs belong to a single mental file - a body of beliefs that the subject takes to be about a single thing. Since the premisses are already unified in this way, there is no need to add an extra identity premiss to connect them, so the inference can proceed without one. In contrast, according to a proponent of this framework, before your discovery that Bertie is Russell you have two distinct 'Bertie' and 'Russell' files. When you discover the identity you merge these two files into one

And in fact the mental files framework lets us be much more sophisticated. Consider your situation as you go about your business before discovering the identity, maintaining (in file theorist's terms) separate 'Bertie' and 'Russell' files. In the story as most naturally told, this situation - failing to realize that the files are about the same person - is not one you have got into through sheer carelessness or perversity. Rather, you are in the situation because you have happened upon streams of testimony expressed using syntactically very different expressions ('Bertie' on the one hand, 'Russell' on the other) and whose contents have so far given you no reason to suspect that they relate the deeds and characteristics of a single individual. When you discover the identity, you merge your two files. But, though you know that Bertie is Russell, you realize that other people may not. So, though you are now operating with a single 'Bertie'/'Russell' file, you also maintain, within the file, a distinction between beliefs tracing to the 'Bertie' stream of testimony and those tracing to the 'Russell' one. This distinction enables you to understand why other people - people not yet aware of the identity - hold the 'Bertie' 
and 'Russell' beliefs they do. And it is a small step from here to the observation that this reason for distinguishing, 'Bertie' and 'Russell' sub-files within your 'Bertie'/'Russell' file might also generate distinctions within your 'Bertie' or 'Russell' file/sub-file itself. Suppose that you have formed your 'Russell' file in a way that has given you no reason to doubt the unity of the testimony stream or the file formed by uptake from it. You might, nevertheless, recognize that other people could, without rational inconsistency, fail to realize that the Russell who wrote 'On Denoting' in 1905 and the Russell who cofounded the Campaign for Nuclear Disarmament in 1957 are the same. By maintaining a distinction between 'Russell the academic philosopher' and 'Russell the peace activist' sub-sub-files within your 'Russell' sub-file, you retain the capacity to understand how it might be rational for someone in this position to form and deploy 'Russell' beliefs.

I take this kind of explanation to be standard among philosophers who have couched their accounts of thought about particulars in terms of the notion of a mental file. ${ }^{25}$ I shall now argue that this standard file-theoretic explanation generates commitment to a specific story about what mental files actually are. I shall approach this story by way of a preliminary discussion of an issue about the metaphysics of ordinary objects.

In a landmark paper on identity across time for ordinary objects ${ }^{26}$, Michael Ayers explored the distinction between 'substances' (ordinary objects) and 'processes'. He then used the distinction to argue against 'four dimensionalism' about ordinary objects: the view that an ordinary object persists across a time interval by having a temporal stage present at each time in the interval, and that the persisting object is in fact a series of momentary or short-lived objects standing to one another in an appropriate continuity relation. I shall give a brief summary of Ayers's discussion, then extract a moral for right accounts of the metaphysics of mental files.

I shall confine this discussion to what I take to be the most important two of Ayers's marks of the object/process distinction.

The first can be explained in terms of what Ayers called the 'parthood principle':

No ordinary object is part of another in the same way as its parts are parts of it.

To understand the principle and see why it should be accepted, consider a horse, on the one hand, and an attack of chicken pox on the other. A horse has parts (head, legs, hooves). And there is a sense in which the horse itself can participate in some larger entity: a horse might be a part of a team of horses all pulling a cart. But, Ayers suggests, these senses of 'part' are distinct. The horse is a 'part' of the team only in that it is a member of the team. The horse's leg is not a mere member of the horse - it is a 'part' of the horse in a much stronger sense; a sense in which no horse is itself a part of anything else. And he suggests that matters are quite different when it comes to an attack of chicken pox. It is easy to distinguish episodes which make up parts of an attack of chicken pox: you feel like you've got a cold; you get spots; you develop a fever; the fever goes away; the spots heal. But there are many processes of which the attack of chicken pox is just as much a part as these episodes are a part of it. If you are suffering from one

${ }^{25}$ Compare Jeshion 204, 2010; Recanati 2012 esp. pp 42-56, 76-146, 181-208; Goodman 2014 §2.

${ }^{26}$ Ayers 1991. 
illness after another, the attack of chicken pox is part of your general malaise. If there is an epidemic of chicken pox going on, your attack is part of the epidemic.

So, on the face of things, consideration of the senses in which they can have and be parts brings out a divide between ordinary objects (like horses) and processes (like attacks of chicken pox): a process is part of other processes in the same way as its parts are parts of it; an ordinary object is not.

Ayers's second mark of the distinction concerns what he calls 'logical unity'. Once again, the distinction he has in mind is most easily brought out using an example. Consider the contrast between a predicate which corresponds to a kind of ordinary thing (like 'human being') and a predicate which corresponds to a kind of event (like 'storm'):

'Human being' is a predicate which combines with many other predicates to create composite predicates which some human beings satisfy some of the time, for example 'adult human being', 'rich human being'. Sometimes our language conceals the complexity of the predicate for the sake of economy (for example, 'baker' is short for 'human being who bakes'). But the composite predicate does not stand for a new kind of thing: there is no new thing that comes into existence when a human being comes to satisfy one of these complex predicates.

'Storm' is a predicate which combines with many other predicates to create composite predicates which some storms satisfy some of the time, for example, 'thunder storm', 'hail storm'. And in these cases the composite predicate does stand for something which is just as much an entity as the overall storm is. The overall storm is a process. But so are the hail storm and the electrical storm: if the overall storm lasts all day, there is no barrier to the claim that at 6 o'clock, when the storm becomes electrical, a new process (an electrical storm) begins.

So we seem to have a second distinction between processes and ordinary objects. In general, for every property that a process of a given kind may have, we are free to say that a process having the property is a new kind of process. But, it seems, to say the same about ordinary objects is just a mistake.

Ayers put his marks of the distinction between substances and processes to work in an argument against four dimensionalism about ordinary objects:

1 Four dimensionalism treats ordinary objects as having process ontology.

2 Ordinary objects do not have process ontology.

So

3 Four dimensionalism should be rejected.

It is obviously not possible to adjudicate whether this argument against four dimensionalism about ordinary objects should be accepted in an appendix to a paper on something else. So I shall not try to assess Ayers's 2. But I shall take it that he is right about 1. To treat a continuant as a series of continuant-stages just is to take it that the continuant has 'parts' in a sense in which it may itself also be a part. Similarly, if a 
continuant is just a series of stages, there is no logical barrier to recognition of shorterlived continuants - shorter series of stages - that come into existence when the longerlived continuant gains a property, and go out of existence when it loses the property again. ${ }^{27}$

Now let us return to the mental files theorist's 'Bertie'/ 'Russell' story rehearsed a few pages ago. This is a story which treats mental files as displaying both of Ayers's marks of process/four dimensionalist ontology. It treats a file as able to have parts in the same sense in which it may itself be a part. (Your 'Russell' file is part of your 'Bertie'/ 'Russell' file in the same sense in which your 'Russell the peace activist' file is part of your 'Russell' file.) And the story draws much of its explanatory power from the possibility of extending it to recognise new files and sub-files as explanatory purposes demand - a new file or sub-file for every kind of rational division among beliefs that we want to explain.

This brings us part-way to the account of the metaphysics of mental files that I want to propose: the right metaphysics for a mental files framework is fourdimensionalist. To get the rest of the way to the account, we need to draw a distinction between kinds of four-dimensionalist view.

The most commonly held four dimensionalist views are forms of what I shall call 'four dimensionalism with ur-elements':

Four dimensionalism with ur-elements - The basic ontological unit is a temporal stage. A continuant is a sequence of temporal stages. Temporal stages are 'more basic' than continuants in that the properties of continuants are derivative from those of their consitutent stages.

\footnotetext{
${ }^{27}$ If you have doubts about Ayers's 1, consider the standard four-dimensionalist solution to the puzzle about fission scenarios. Suppose that initial protagonist Derek splits into duplicate persons Lefty and Righty; surely (it seems) Derek survives this transaction - being duplicated is not dying. But if Derek has survived in the persons of Lefty and Righty, then Derek is Lefty and Derek is Righty. However, Lefty and Righty are not identical - already they are going their separate ways. So the claims that survival is identity and that Derek survives in the persons of Lefty and Righty are in apparent tension with the fact that identity is an equivalence relation: since identity is an equivalence relation, the combination 'Derek = Lefty', 'Derek $=$ Righty', 'Lefty $\neq$ Righty' cannot be. According to a standard four-dimensionalist account of fission cases, Lefty and Righty are distinct series of person-stages which share an initial segment. During the time when there is just Derek, the two series coincide. Derek survives the duplication because a person is just a series of person stages standing to one another in a continuity relation, and a person considered at time $t$ counts as having survived until $t+n$ iff there is some person-stage in existence at $t+n$ which stands in the continuity relation to the stage of the person that was in existence at t. The Derek stages stand in this continuity relation to both the Lefty stages and the Righty stages. (This is why Derek survives in the persons of both Lefty and Righty.) But Lefty and Righty are distinct series of person stages (Lefty $\neq$ Righty). And the post-split Lefty and Righty stages do not stand in the continuity relation to one another. (Compare Lewis 1983; Sider 2001 202-205; and many others) This solution treats the 'Derek' series of person-stages as making up a part of each of the 'Lefty' and 'Righty' series in just the same sense as a shorter series of 'Derek' stages is a part of Derek. Similarly, the standard four-dimensionalist solution to the puzzle of the statue and the lump of clay treats the lump itself as a series of temporal stages, and the statue as a shorter series within this longer series, coming into existence when the lump becomes statueshaped, and ceasing to exist if the clay is squashed back into mere lumpishness. (Compare Sider 2001 200201 ; and many others.)
} 
Standard 'perdurantist' views of material things are views of this kind. To see this, consider the standard perdurantist account of how to reconcile the fact that material things change across time with the Second Law of Idenity (if $\mathrm{x}$ and $\mathrm{y}$ are identical, they have all their properties in common). According to this account, the fact that the same object can be $F$ at $\mathrm{t}$ but not- $F$ at $\mathrm{t}+\mathrm{n}$ is explained in terms of the properties of the object's temporal stages taken as prior: the t-stage of the object is $F$; its $\mathrm{t}+1$ stage is not; the object's pattern of $F$-instantiation is explained in terms of the F-ness or not of the constitutent stages.

But a commitment to temporal stages which are the fundamental bearers of properties is not a necessary feature of a four dimensionalist view. The alternative is what I shall call 'pure process four dimensionalism':

Pure process four dimensionalism A continuant is ontologically derivative from a process. We can define stages of the continuant by specifying intervals within the timeframe over which the process unfolds. But the continuant's properties are not to be explained in terms of properties of its stages taken as prior. Both the continuant's properties and those of the stages into which it might be divided are to be explained in terms of the properties of the underlying process.

For example, consider a process of performing Hamlet, engaged in by some group of players. It is commonplace to recognise a continuant derivative from this process $-\mathrm{a}$ particular performance of Hamlet. This process has temporal parts - acts, scenes, lines. But the properties of the whole performance are not derivative from those of some privileged basic range of temporal parts. What it is for the whole performance to be a masterpiece cannot be explained in terms of properties of individual speakings of lines taken as prior. For what it is for an individual line to be well-delivered depends on how the others are delivered, and on the fact that the line is being delivered as part of a performance of Hamlet (rather than a performance of Rosenkranz and Guildenstern are Dead).

With this general distinction in place, it is a short step to the conclusion that the most plausible four dimensionalism for a mental file theorist is pure process four dimensionalism.

To see this, note first that the alternative, ur-elemental, form of mental files four dimensionalism is radically implausible. This kind of view would take the ontologically basic elements of the files framework to be momentary file stages. But it is doubtful that it makes sense to talk about propositional attitudes as held at an instant. And even if this does make sense, if mental files are to play their role in explaining rational clusterings among a subject's beliefs, the subject's mental file considered at a time will have to include not only 'explicit' beliefs (beliefs the holding of which at a time is explained in terms of the representational properties of some mental vehicle tokened by the subject at the time) but 'implicit' ones too (beliefs reachable from explicit beliefs by 'brief and trivial' steps). If to talk about the subject's mental file at a time we have to talk about the file as it evolves over an interval, we have already given up on the ur-elemental suggestion that the properties of the momentary file are prior in order of explanation to those of the longer files of which it is a part. 
Note also that there is an obvious candidate to be the process from which we might say that mental files are derivative: the process of maintaining a body of beliefs treated as about a single thing. In terms of the proposal of the main body of the paper, this is the process of achieving and sustaining cognitive focus on an object. But for the purposes of this appendix, the specific details about the process that underlies a mental file are not important. Any mental files theorist will recognise some process as the process that determines how the file evolves over time. I suggest that a mental file stands to this process as a performance of Hamlet stands to the underlying process of performing Hamlet. In each case, it is the process that is ontologicaly basic: the properties of the continuant are to be explained in terms of those of the process that lies beneath.

Does this result warrant the puritanical abstinence from talk about mental files practised in the main body of the paper? That depends on the answers to two questions. Is anything substantial gained by talking about mental files rather than the processes that underpin them? Is anything lost by doing so? My own view is that the answers to these questions are 'No' and 'Yes'. To employ the vocabulary of mental files is to state an account of thought about particulars at a level other than that at which the predicates the account employs will need to be explained. In the absence of an ill-natured list of the shortcomings of such accounts, to have pointed this out is not yet to have shown that we should not talk about mental files. But I hope to have said enough to explain why I have not stated my own mental files view in 'mental files' terms.

\section{References}

1. Ayers, M. (1991). 'Substance: Prolegomena to a Realist Theory of Identity'. Journal of Philosophy 88 (2): pp. 69-90.

2. Bach, K. (2010). 'Getting a Thing into a Thought'. In New Essays on Singular Thought, edited by R. Jeshion. Oxford: Oxford University Press.

3. Boghossian, P. (2003) 'The Normativity of Content'. Philosophical Issues 13: 3145.

4. Bratman. M. (1987) Intentions, Plans, and Practical Reason. Stanford, CA: CSLI.

5. Braun, D. (2005). 'Empty Names, Fictional Names, Mythical Names'. Noûs 39 (4): 596-631.

6. Campbell, J. (1999). 'Immunity to Error Through Misidentification and the Meaning of a Referring Term'. Philosophical Topics 26 (1\&2): pp. 89-104.

7. Campbell, J. (2002). Reference and Consciousness. Oxford: Oxford University Press.

8. Crane, T. (2013). Objects of Thought. Oxford: Oxford University Press.

9. Dickie, I. (2015) Fixing Reference. Oxford: Oxford University Press. 
10. Dickie, I. (forthcoming) 'The Subtle Lives of Descriptive Names'. In Oxford Studies in the Philosophy of Language vol. 1.

11. Evans, G. (1982). The Varieties of Reference. Edited by John McDowell. Oxford: Oxford University Press.

12. Evans, G. (1985). 'Understanding Demonstratives'. In Collected Papers. Oxford: Oxford University Press.

13. Garcia-Carpintero, M. (2010). 'Fictional Singular Imaginings'. In New Essays On Singular Thought, edited by Robin Jeshion. Oxford: Oxford University Press.

14. Goodman, R. (2014). 'Against the Mental Files Conception of Singular Thought' Review of Philosophy and Psychology

15. Greco, J. (2010) Achieving Knowledge. Cambridge: Cambridge University Press.

16. Jeshion, R. (2002). 'Acquaintanceless De Re Belief'. In Meaning and Truth: Investigations in Philosophical Semantics, edited by J. Campbell, M. O’Rourke, and D. Shier. New York: Seven Bridges Press.

17. Jeshion, R. (2004). 'Descriptive Descriptive Names'. In Descriptions and Beyond, edited by M. Reimer and A. Bezuidenhout. Oxford: Clarendon Press.

18. Jeshion, R. (2010). 'Singular Thought: Acquaintance, Instrumentalism, and Cognitivism'. In New Essays on Singular Thought, edited by R. Jeshion. Oxford: Oxford University Press.

19. Lewis, D. (1974) 'Radical Interpretation'. Synthese 27 (3-4): pp. 331-44.

20. Lewis, D. (1983) 'Survival and Identity' in Lewis Philosophical Papers vol. 1. Oxford: Oxford University Press.

21. McDowell, J. (1977). 'On the Sense and Reference of a Proper Name'. Mind 86 (342): pp. 159-185.

22. McDowell, J. (1984). 'De Re Senses'. Philosophical Quarterly 34 (136): pp. 283294.

23. Perry, J. (1987) 'Indexicals and Deonstratives'. In A Companion to the Philosophy of Language, edited by B. Hale and C. Wright. Oxford: Blackwell.

24. Quine, W. v. O (1960). Word and Object. Cambridge MA: MIT Press.

25. Recanati, F. (2010). 'Singular Thought: In Defence of Acquaintance'. In New Essays On Singular Thought, edited by R. Jeshion. Oxford: Oxford University Press.

26. Recanati, F. (2012). Mental Files. Oxford: Oxford University Press.

27. Recanati, F. (forthcoming). 'Indexical Thought: The Communication Problem'. In About Oneself, edited S. Torre and M. Garcia-Carpintero. Oxford: Oxford University.

28. Reimer, M. (2004). 'Descriptively Introduced Names'. In Descriptions and Beyond, edited by M. Reimer and A. Bezuidenhout, pp. 613-629. Oxford: Oxford University Press.

29. Russell, B. (1956a). 'The Philosophy of Logical Atomism'. In Logic and Knowledge: Essays 1901-1950, edited by R. Marsh. London: Allen and Unwin.

30. Russell, B. (1956b). 'On Denoting'. In Logic and Knowledge: Essays 1901-1950, edited by R. Marsh. London: Allen and Unwin.

31. Shah, N. and J. D. Velleman. (2005) 'Doxastic Deliberation'. Philosophical Review 114: pp. 297-534.

32. Sider, T. (2001) Four Dimensionalism. Oxford: Oxford University Press. 
33. Stojnic, U. (2018) 'Review of Fixing Reference'. Australasian Journal of Philosophy vol 96 no. 1 pp. 189-193.

34. Strawson, P. F. (1959) Individuals. London: Methuen.

35. Taylor, K. (2000). 'Emptiness without Compromise'. In Empty Names, Fiction, and Puzzles of Non-Existence, edited by A. Everett and T. Hofweber. Stanford: CSLI.

36. Velleman, J. D. (2000). 'On the Aim of Belief' in Velleman The Possibility of Practical Reason. Oxford: Oxford University Press.

37. Williams, J. R. G. (2007). 'Eligibility and Inscrutability'. Philosophical Review 116 (3): pp. 361-399. 